\title{
Braços nas argolas e sorrisos nos rostos: narrativas museais sobre a escravidão
}

\author{
[ Arms in rings and smiling faces: museum narratives on slavery
}

\author{
Vinícius Oliveira Pereira ${ }^{\mathrm{I}}$
}

\section{Alexandra Lima da Silva ${ }^{2}$}

RESUMO - O tráfico transatlântico de pessoas escravizadas e a escravidão são marcados por uma multiplicidade de sentidos. Nesse contexto, o artigo debruça-se sobre a instituição que tem propagado narrativas e imagens sobre o tema no Brasil: o museu. O objetivo é mapear e identificar os espaços museais dedicados à temática no país. Visamos, a partir da análise de imagens dos acervos disponíveis na internet e das postagens publicadas nas redes sociais dos museus identificados, compreender quais são as narrativas sobre a escravidão visibilizada nesses espaços. Entre os resultados do artigo, destacam-se a quase ausência de espaços dedicados a divulgar e preservar a memória da escravidão e a presença hegemônica de narrativas que enfatizam a dimensão da violência da escravidão. PALAVRAS-CHAVE. Museu; escravidão; memória. · ABSTRACT · The transatlantic trafficking of enslaved people and the slavery institution are characterized by a multiplicity of meanings. This article zooms in on the museum, an institution that has been responsible for spreading images and narratives on the subject in Brazil. Our aim is to map and pinpoint the museum spaces dedicated to the theme in the country. Then, by analyzing digital images of collection items available online and texts posted on the social media accounts of the mapped museums, we aim to understand which narratives on slavery are made visible in these spaces. From our findings, the following stand out the almost complete absence of spaces dedicated to disseminating and preserving the memory of slavery, and the hegemonic presence of narratives that highlight the violent dimension of slavery. · KEYWORDS - Museum; slavery; memory.

Recebido em 25 de maio de 2021

Aprovado em I8 de agosto de $202 \mathrm{I}$

PEREIRA, Vinícius Oliveira; SILVA, Alexandra Lima da. Braços nas argolas e sorrisos nos rostos: narrativas museais sobre a escravidão. Revista do Instituto de Estudos Brasileiros, Brasil, n. 80, p. 33-54, dez. 2021.

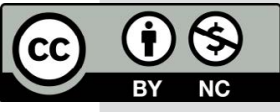

DOI: https://doi.org/Io.II606/issn.23I6-90IX.vri8op33-54

I Universidade do Estado do Rio de Janeiro (UERJ, Rio de Janeiro, RJ, Brasil).

2 Universidade do Estado do Rio de Janeiro (UERJ, Rio de Janeiro, RJ, Brasil). 


\section{Entre trauma e brincadeira: sentidos mobilizados em torno da escravidão}

Inverno de 20I9, Mariana33, Minas Gerais. A manhã ensolarada é um convite a uma caminhada no centro histórico da cidade mineira. O município tem as ruas repletas de turistas. Câmeras e celulares registram os detalhes dos edifícios coloniais, reminiscências que fomentam a imaginação sobre como era(m) a(s) vida(s) no Brasil Colônia. Na Praça Central, em frente à Câmara Municipal e cercado pela Arquidiocese de Mariana e pela Igreja Nossa Senhora do Carmo, encontra-se o pelourinho da cidade, com suas argolas e correntes. Para determinadas pessoas que o observam, o monumento - nas palavras de Pierre Nora (I993), um lugar de memória 4 - pode remeter às injustiças, dores e violências perpetradas em um período em que braços eram presos em argolas e corpos eram violentados em praça pública.

A encenação, no mínimo inusitada, articula em uma mesma cena braços nas

3 Em novembro de 20I5, a cidade de Mariana (MG) foi atingida por rejeitos de uma barragem da empresa Samarco. O rompimento, considerado o mais grave desastre ambiental do país, matou I9 pessoas e afetou todo o ecossistema do Rio Doce. Segundo o Movimento de Atingidos por Barragens (MAB), cerca de 2 milhões de pessoas foram atingidas, mas apenas 8.537 foram indenizadas por danos gerais e 254 mil indenizadas por desabastecimento de água.

4 Sobre a noção de lugar de memória, o historiador Pierre Nora (I993, p. 2I-22) afirma: "São lugares, com efeito nos três sentidos da palavra, material, simbólico e funcional, simultaneamente, somente em graus diversos. Mesmo um lugar de aparência puramente material, como um depósito de arquivos, só é um lugar de memória se a imaginação o investe de uma aura simbólica. Mesmo um lugar puramente funcional, como um manual de aula, um testamento, uma associação de antigos combatentes, só entra na categoria se for objeto de um ritual [...]. É material por seu conteúdo demográfico; funcional por hipótese, pois garante, ao mesmo tempo, a cristalização da lembrança e sua transmissão; mas simbólica por definição visto que caracteriza por um acontecimento ou uma experiência vividos por um pequeno número uma maioria que deles não participou”. 
argolas e sorrisos nos rostos ${ }^{5}$. A combinação desses elementos, inimagináveis em outros momentos históricos, tem como protagonista uma família branca de turistas, que utilizam os celulares para registrar a cena. A desenvoltura com que interagem com o monumento não deixa espaço para dúvidas: eles conhecem a função social desempenhada pelo pelourinho em outros tempos. A família branca sabe que naquele monumento corpos negros foram violados. Apesar de o pelourinho poder ser interpretado por determinados grupos sociais como representação de uma memória sensível, nenhum constrangimento ou pudor foi capaz de impedir a trágica encenação ${ }^{6}$.

$\mathrm{O}$ fato relatado parece ser recorrente em Mariana. Em pesquisa realizada na internet, é possível encontrar reportagens que retratam situações semelhantes à testemunhada naquele inverno de 20I9. Em reportagem do Jornal Ponto Final, publicada em 20I7, verifica-se, por exemplo:

“Não adianta só algemar, tem que chicotear também. Chicoteia!", gritava um turista, em tom de brincadeira. A alguns metros dele, uma outra visitante posava para fotos no pelourinho da Praça Minas Gerais. Eles estavam com um grupo de pessoas e tinham acabado de deixar a Câmara Municipal. Muitos com uma câmera na mão, bonés para despistarem o sol e garrafinhas de água. Era uma tarde quente de agosto. Outros repetiram o ato e esboçaram enormes sorrisos enquanto eram clicados. (FERNANDES, 20I7).

O repórter responsável pela matéria procurou a Secretaria de Cultura, Turismo e Patrimônio da cidade, responsável pelo pelourinho, a fim de relatar o ocorrido e solicitar um posicionamento do secretário:

"Não vejo as fotografias como maldade, desprezo ou discriminação a uma classe ou a um povo”, diz o secretário da pasta, Efraim Rocha. Ele, no entanto, afirma que os turistas posam para fotos de forma "inconsequente". Seja isso ou não uma forma de desprezo, o secretário vê a ação como "uma manifestação de viagem a um passado distante”. Um passado de escravidão. (FERNANDES, 20I7).

O secretário de Cultura, Turismo e Patrimônio citado na reportagem parece compartilhar com aqueles grupos de turistas a mesma compreensão sobre o que a escravidão de africanos representa. De acordo com tal entendimento, o pelourinho é um

5 A possibilidade de se relacionar com um símbolo da escravidão no Brasil de forma jocosa é indicativo da presença marcante do racismo em nossa sociedade. Grada Kilomba (20I9) aponta que uma das consequências do racismo é a desumanização das pessoas negras, tornando-as o outro, o exótico da branquitude. Nesse cenário, as chances de tecer relações empáticas com as histórias dos sujeitos escravizados são quase nulas. Dessa forma, os museus que se propõem a abordar o tema precisam levar em consideração a necessidade de romper a lente do racismo que tem sido utilizada pela sociedade brasileira para olhar sua própria história, intrinsecamente conectada à instituição da escravidão.

6 O fato ocorrido em Mariana (MG) realinhou o problema de pesquisa de doutorado de onde o presente artigo deriva. A investigação, que a princípio estava interessada em discutir as representações da cultura afro-brasileira nos espaços museais, debruçou-se sobre os modos pelos quais a escravidão de africanos é representada nos museus. Neste artigo, apresentamos resultados parciais da pesquisa de doutorado. 
fragmento de um período da história do Brasil, e as performances realizadas em frente ao monumento se configuram como tentativas de experienciar, mesmo que de forma jocosa, a situação vivenciada por milhares de sujeitos que foram escravizados ao longo de mais de 300 anos. Myrian Sepúlveda dos Santos sublinha em suas pesquisas as consequências de assim interpretar esse período da história brasileira. De acordo com a socióloga,

Despite preserving the past, historical narratives, museums, monuments and archives also involve forgetting. The narratives explain the period's economic systems, political regimes and social interactions, yet in doing so, they obliterate the uniqueness of slavery as an event and turn the suffering of those slaves into just one historical example among many others. As part of History, the torture and humiliation of millions of human beings, who were diminished and classified as members of an inferior race located somewhere between humanity and animality, appear as merely an historical phase that had to be overcome. (SANTOS, 2008, p. I64).

[Apesar de preservar o passado, narrativas históricas, museus, monumentos e arquivos também implicam esquecimento. As narrativas explicam os sistemas econômicos, regimes políticos e interações sociais do período, mas, ao fazê-lo, apagam a singularidade da escravidão e transformam o sofrimento daqueles escravos em apenas um exemplo histórico entre muitos outros. Como parte da história, a tortura e a humilhação de milhões de seres humanos, que foram desvalorizados e classificados como integrantes de uma raça inferior situada entre a humanidade e a animalidade, aparecem apenas como uma fase histórica a ser superada7.]

Contrastando com a situação relatada por Santos (2008), a Conferência Mundial contra o Racismo, Discriminação Racial, Xenofobia e Intolerância Correlata, promovida pela Organização das Nações Unidas (ONU), em 200I, na cidade de Durban, África do Sul, considerou o tráfico transatlântico de pessoas escravizadas e a escravidão como crimes contra a humanidade. Na conferência, afirmou-se ainda que o racismo contemporâneo pode ser entendido como uma consequência desses fatos históricos. No documento com a declaração e o plano de ação da conferência, que tem o Brasil como um dos países signatários, consta:

Reconhecemos que a escravidão e o tráfico escravo, incluindo o tráfico de escravos transatlântico, foram tragédias terríveis na história da humanidade, não apenas por sua barbárie abominável, mas também em termos de sua magnitude, natureza de organização e, especialmente, pela negação da essência das vítimas; ainda reconhecemos que a escravidão e o tráfico escravo são crimes contra a humanidade e assim devem sempre ser considerados, especialmente o tráfico de escravos transatlântico, estando entre as maiores manifestações e fontes de racismo, discriminação racial, xenofobia e intolerância correlata; e que os Africanos e afrodescendentes, Asiáticos e povos de origem asiática, bem como os povos indígenas foram e continuam a ser vítimas destes atos e de suas consequências. (CONFERÊNCIA de Durban, 200I, p. I2).

7 Inserimos, logo após os trechos citados em outro idioma, a tradução livre de nossa autoria. 
O documento produzido ao longo da Conferência de Durban não nega a historicidade da escravidão. No entanto, a dimensão do trauma e as consequências contemporâneas das violências perpetradas ao longo de mais de 300 anos de história são visibilizados. Nesse sentido, historiadoras como Ana Lúcia Araújo (202Ia, p. 2) têm afirmado: "[...] current debates about slavery are more than simple attempts to come to terms with the past but are rather associated with persistent racism and racial inequalities that prevail in former slave societies or countries where slavery existed" (“...] os debates atuais sobre a escravidão são mais do que simples tentativas de chegar a um acordo com o passado, mas estão associados ao racismo persistente e às desigualdades raciais que prevalecem em antigas sociedades escravistas ou países onde a escravidão existia”).

O cenário descrito acima é indicativo da complexidade das teias que marcam a produção de narrativas sobre a escravidão, que mobiliza, de acordo com o contexto e o grupo social, diferentes significados. Se, para determinada parcela da sociedade, a escravidão de africanos representa apenas um período da história, para outros segmentos sociais, o evento, além de sua dimensão histórica, é marcado pelo trauma, e seus impactos permanecem visíveis na sociedade contemporânea. Diante de tal multiplicidade de sentidos, debruçamo-nos sobre uma instituição que, segundo Santos (2008), tem se dedicado a construir narrativas sobre a escravidão no Brasil: o museu.

Nesse sentido, propomo-nos, neste artigo, a realizar um ensaio sobre diferentes aspectos do espaço museal, de modo a pensar como tal instituição transita por meio desse emaranhado de sentidos sobre a escravidão e em que medida ela contribui, através de textos institucionais, organização do acervo, exposições e imagens publicadas em redes sociais, para a (re)configuração da batalha semântica em que se encontra o tema do tráfico transatlântico de pessoas escravizadas e da escravidão no Brasil.

\section{Museus sobre escravidão no Brasil: construindo um panorama}

A extensa produção no campo da historiografia brasileira sobre a escravidão tem demonstrado a amplitude dessa instituição no território nacional (ALENCASTRO, 20I8; KLEIN, 20I8). Nesse sentido, pode-se dizer que a história do Brasil está intrinsecamente ligada à história do tráfico transatlântico de pessoas escravizadas. Luiz Felipe de Alencastro afirma, por exemplo, que a instituição escravocrata esteve presente em diferentes períodos da história brasileira:

O tráfico transatlântico de escravos africanos tomou no Brasil uma dimensão inédita no Novo Mundo. Do século XVI até I850, no período colonial e no imperial, o país foi o maior importador de escravos africanos das Américas. Foi ainda a única nação independente que praticou maciçamente o tráfico negreiro, transformando o território nacional no maior agregado político escravista americano. Consubstancial à organização do Império do Brasil, a intensificação da importação de escravos africanos após I822 explica a longevidade do escravismo até a sua abolição. (ALENCASTRO, 20I8, p. 57).

A perspectiva trazida por Alencastro (20I8) é interessante para pensarmos a longevidade do escravismo no Brasil. As interpretações lineares sobre a história 
do país costumam dividi-la em três momentos: período colonial, período imperial e período republicano. Durante os dois primeiros períodos, que somam 359 anos, as relações políticas, econômicas e sociais foram, inevitavelmente, mediadas pela instituição da escravidão. Em outras palavras, podemos dizer que a escravidão constituiu a base da maior parte da história do país.

Apesar da vinculação quase intrínseca entre a escravidão e a história do Brasil, o tema tem tido pouca ou nenhuma notoriedade no debate público e nas representações sobre a memória nacional. Em termos institucionais, por exemplo, são raros os museus preocupados em abordar a temática de forma exclusiva, o que confirma a análise tecida pela historiadora Ana Lucia Araújo, que, em diálogo com Achille Mbembe, afirma:

As expressed by Achille Mbembe, the "slave" remained an undesirable figure in the museum, where most attempts to tell the history of slavery portray bondspeople as an "appendix to another history, a citation at the bottom of a page devoted to someone else, to other places, to other things". (ARAÜJO, 202Ib, p. 4).

[Como expresso por Achille Mbembe, a "escravidão" continua uma figura indesejável nos museus, onde a maioria das tentativas de contar a história da escravidão retrata os escravizados como um "apêndice de outra história, uma citação no fim de uma página dedicada a outra pessoa, a outros lugares, a outras coisas".]

Em um cenário marcado por instituições que apenas tangenciam o tema da escravidão em suas exposições, interessa-nos, tendo em vista os limites de um artigo, pensar, de modo prioritário, as instituições que indicaram abordar de forma exclusiva a temática da escravidão. Conforme demonstram os dados coletados na plataforma desenvolvida pelo Instituto Brasileiro de Museus (IBRAM, s. d.) ${ }^{8}$, o país possui atualmente 3.832 museus cadastrados. Desse total, identificamos treze 9 instituições que possuem exposições e acervos relacionados à escravidão e apenas seis que se dedicam

8 Os dados foram coletados da Plataforma Museus do Brasil do Ibram. Nela, o Cadastro Nacional de Museus faz o mapeamento e a atualização das informações dos museus brasileiros.

9 São eles: Museu do Negro (RJ), Museu da História e da Cultura Afro-Brasileira (MUHCAB, RJ), Museu Histórico e Pedagógico Doutor Cesário Motta Júnior (SP), Museu Histórico Municipal de Sete Lagoas (MG), Museu Xucurus de História, Arte e Costumes (AL), Cafua das Mercês (Museu do Negro, MA), Museu Casa do Benin (BA), Museu do Negro de Campinas (SP), Museu Afro Brasil (SP), Centro de Referência da Cultura Negra (MG), Museu Vivo do São Bento (RJ), Casarão (ES), Museu Escravo Jacó (RN). Avaliamos que o número de museus que possuem alguma exposição dedicada à escravidão pode ser maior do que o encontrado em nosso levantamento. Na cidade do Rio de Janeiro, por exemplo, o Museu Histórico Nacional possui alguns objetos relacionados ao tema em seu acervo. No entanto, o fato de não mencionar a escravidão como uma das temáticas de suas exposições pode ser indicativo do que foi apontado por Achille Mbembe e Ana Lucia Araújo (202Ib). 
exclusivamente ao tema ${ }^{\text {Io }}$. No mapa apresentado na Figura I, é possível identificar as cidades e estados onde se localizam os seis museus dedicados à temática.

\section{Mapa dos museus sobre escravidão no Brasil}
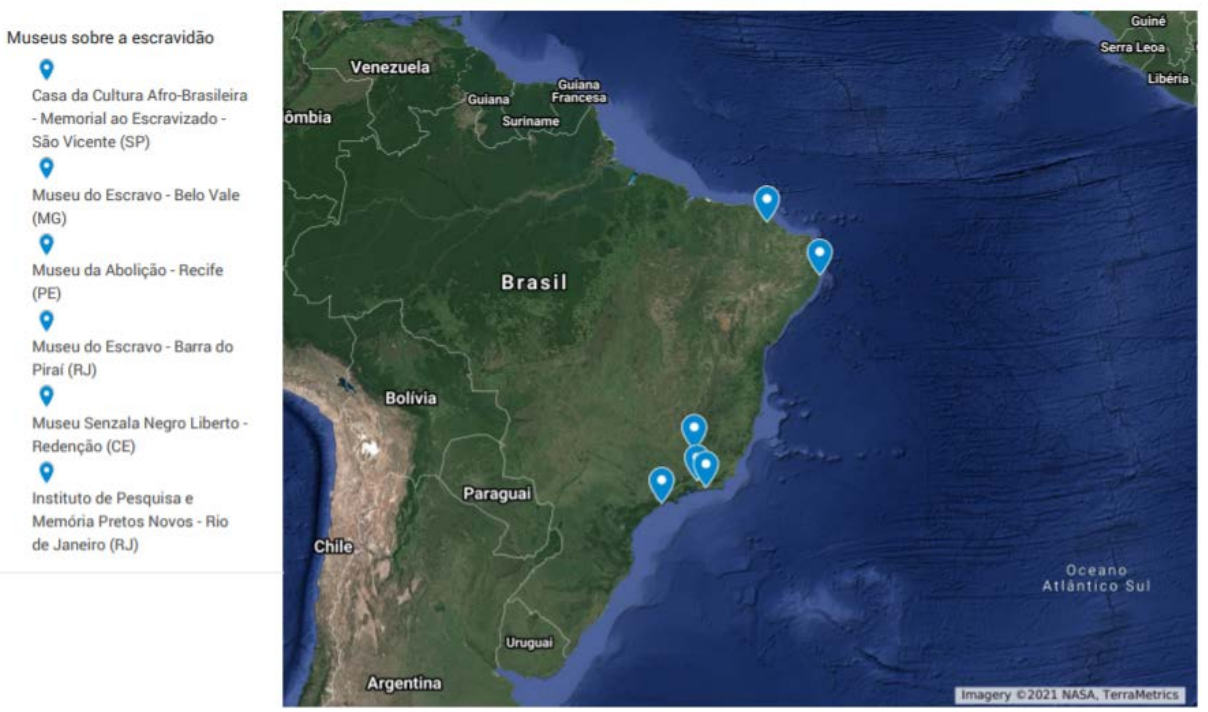

Figura I - Mapa dos museus sobre escravidão no Brasil. Fonte: Google Maps, 202I

O mapa evidencia que os museus dedicados à escravidão se concentram em apenas duas regiões do país: Nordeste e Sudeste. A ausência de museus semelhantes em outras regiões do Brasil contrasta com o fato de a instituição da escravatura ter se feito presente em todo o território nacional:

Os escravos foram importantes tanto na área rural e na mineração como nas áreas urbanas, e, devido à falta de competição de brancos livres, podiam ser encontrados em todo o país, como a principal força de trabalho. Embora houvesse concentração de escravos nas fazendas ou nas áreas de mineração, em todos os municípios brasileiros podíamos encontrar fogos com escravos. Assim, o Brasil se parecia mais com as Índias Ocidentais, com sua população negra dominante, do que com os Estados Unidos, que concentraram mais de $90 \%$ de seus escravos em apenas uma região do país, o Sul. Mesmo no período posterior a I850, não havia impedimentos para migração interna, e movimentavam-se os escravos livremente por todo o Império. (KLEIN, 20I8, p. I90).

O historiador americano Herbert Klein (20I8) realizou uma demografia da

Io Na Plataforma Museus do Brasil é possível ter acesso ao cadastro de museus de todo o país. Para determinar o número de museus dedicados à instituição da escravatura, foram utilizadas no campo de pesquisa quatro palavras como filtro: (I) escravo, (2) escravizado, (3) escravidão e (4) abolição. Apenas as seis instituições citadas no trabalho têm como foco exclusivo a temática. Outras instituições foram encontradas, mas elas não se dedicam exclusivamente à escravidão: apenas parte do acervo é relativa ao tema. 
escravidão no Brasil e constatou não apenas a longevidade da instituição, mas sobretudo seu alcance geográfico. De acordo com o pesquisador, diferentemente dos Estados Unidos, país onde a maior parte da população escravizada estava localizada em uma única região, no Brasil a instituição da escravidão era extremamente ramificada. Nesse sentido, o fato de termos museus sobre a temática em somente seis cidades distribuídas em duas regiões do país pode ser entendido como uma expressão da pouca ou ausente atenção do poder público à preservação dessa memória.

Além da localização das seis instituições identificadas, a pesquisa realizada na plataforma desenvolvida pelo Ibram possibilitou a coleta de mais dados sobre os museus dedicados à temática da escravidão. No Quadro I, podemos encontrar informações a respeito do ano de fundação de cada museu e a esfera do governo responsável pela instituição.

\begin{tabular}{|c|c|c|c|}
\hline Instituição & Fundação & Esfera & Localização \\
\hline $\begin{array}{c}\text { Casa da Cultura Afro-Brasileira } \\
\text { - Memorial ao Escravizado* }\end{array}$ & I976 & Municipal & São Vicente (SP) \\
\hline Museu do Escravo & I977 & Municipal & Belo Vale (MG) \\
\hline Museu da Abolição & I983 & Federal & Recife (PE) \\
\hline Museu do Escravo & I997 & Privado & Barra do Piraí (RJ) \\
\hline Museu Senzala Negro Liberto & 2003 & Privado & Redenção (CE) \\
\hline $\begin{array}{c}\text { Instituto de Pesquisa e } \\
\text { Memória Pretos Novos }\end{array}$ & 2005 & Privado & Rio de Janeiro (RJ) \\
\hline
\end{tabular}

Quadro I- Museus dedicados à escravatura ou aos sujeitos

escravizados. Fonte: os Autores, 202I

*Até dezembro de 2014, a instituição era denominada Museu dos Escravos. Em janeiro de 2015, o museu foi reinaugurado e, após consulta à comunidade, recebeu uma nova nomenclatura: Casa da Cultura Afro-Brasileira - Memorial ao Escravizado. A mudança pode ser um reflexo das discussões contemporâneas do campo da historiografia da escravidão, que tem utilizado a palavra "escravizado" em vez de "escravo" para demonstrar a construção sócio-histórica dessa condição e evitar uma essencialização do termo. O movimento também pode ser discutido a partir das contribuições de Paul Gilroy. De acordo com o historiador britânico, a escravidão torna-se um tema indesejado para aqueles que buscam tecer conexões com tradições africanas como forma de construir uma identidade negra positiva. No movimento de valorização dos grandes feitos das sociedades tradicionais africanas, visibilizar de algum modo as histórias sobre o tráfico transatlântico de pessoas escravizadas torna-se um contrassenso. Dessa forma, a negação por parte de determinados setores da sociedade organizada brasileira em tratar da temática pode ser vista como uma forma de evitar um tema sensível e fortalecer o sentimento de etnicidade (GILROY, 2012).

Um aspecto que se destaca na observação do Quadro I é o fato de $50 \%$ das instituições dedicadas ao tema serem privadas, ou seja, criadas não por força de políticas públicas, e sim por iniciativas de determinado grupo de pessoas. Uma 
particularidade que marca os três museus privados é a dimensão material e histórica de suas sedes, tornando-as parte dos acervos disponibilizados ao público. O Museu Senzala Negro Liberto (CE) e o Museu do Escravo (RJ), por exemplo, estão sediados, respectivamente, em um antigo engenho de açúcar e em uma antiga fazenda de café. Já o Instituto de Pesquisa e Memória Pretos Novos (RJ) está localizado em um sítio arqueológico onde foi encontrada uma série de restos mortais de pessoas escravizadas.

Em pesquisa mais detalhada no portal do Ibram sobre as seis instituições que constam no Quadro I, verificou-se a quase ausência de arquivos históricos nesses espaços. Dos seis museus listados, apenas o Museu da Abolição (PE) e o Museu do Escravo (MG) possuem arquivos históricos. No entanto, nenhum dos dois espaços tem como tarefa disponibilizar os arquivos ao público. $O$ fato de não haver disponibilização de arquivos por parte dos seis museus diminui a possibilidade de essas instituições atuarem também como locais de pesquisa, pois suas ações limitam-se, exclusivamente, à organização de exposições e à recepção do público.

Apesar de o tema da escravidão ser um campo consolidado na historiografia brasileira, a análise da tipologia de acervo dos museus indicou que apenas o Museu da Abolição (PE) definiu "história" como a tipologia de seu acervo. A Casa da Cultura Afro-Brasileira - Memorial ao Escravizado (SP) e o Museu do Escravo (MG) definiram "antropologia e etnografia", enquanto o Instituto de Pesquisa e Memória Pretos Novos (RJ) indicou "antropologia e arqueologia". Nos cadastros do Museu do Escravo (RJ) e do Museu Senzala Negro Liberto (CE), não consta a tipologia dos acervos.

Não obstante a indicação das diferentes tipologias, os museus possuem alguns pontos de similaridade para além da temática da escravidão. Destacamos, de imediato, a dificuldade orçamentária das instituições e os poucos recursos materiais e humanos de que dispõem para a realização das ações cotidianas. O Museu da Abolição (PE), por exemplo, o único federal, precisou ser fechado por pelo menos duas vezes desde sua inauguração, em I983, devido à falta de recursos financeiros e humanos. O Instituto de Pesquisa e Memória Pretos Novos (RJ), localizado em uma casa onde foram achados restos mortais de milhares de africanos recém-chegados ao Brasil ${ }^{\text {II }}$, é uma instituição privada e tem captado recursos para manutenção de suas atividades por meio de editais públicos e convênios com a Prefeitura Municipal do Rio de Janeiro. Esse museu localiza-se em uma região da cidade do Rio de Janeiro que recebeu um grande volume de recursos públicos por conta das reformas urbanas com vistas à recepção dos eventos internacionais realizados na cidade em 2014 (Copa do Mundo de Futebol) e 2016 (Olimpíadas). Todavia, são muitos os relatos das dificuldades relativas aos repasses de recursos públicos do governo municipal para o

II Em janeiro de I996, a família Guimarães dos Anjos estava realizando uma reforma em sua casa, localizada na Zona Portuária da cidade do Rio de Janeiro, quando descobriu uma série de restos mortais no local. Mais tarde, descobriu-se que a casa foi construída sobre o antigo cemitério dos Pretos Novos, local onde eram enterrados os africanos que não resistiam à longa travessia do Atlântico. No site do Instituto de Pesquisa e Memória Pretos Novos, podem ser encontradas mais informações sobre a história do cemitério e da instituição (IPN, s. d.). No que diz respeito à história do Cemitério dos Pretos Novos, o trabalho do historiador Júlio César Medeiros de S. Pereira (2006) é uma importante referência. 
financiamento das ações do referido instituto, como Virgílio (20I7) noticiou. Apesar dos limites financeiros, o Instituto de Pesquisa e Memória Pretos Novos (RJ) tem desenvolvido uma série de atividades a partir de parcerias com setores do movimento negro e grupos acadêmicos. $\mathrm{O}$ conjunto de iniciativas tem atraído um maior número de visitantes, como demonstram Francine Saillant e Pedro Simonard:

The institute is frequently visited in November (Black Awareness month) and also during events involving Afro-Brazilian culture. Moreover, the house is increasingly visited by AfroBrazilians and tourists of the African diaspora who are interested in places of remembrance of slavery all over the world. (SAILLANT; SIMONARD, 20I2, p. 224).

[O instituto é frequentemente visitado em novembro, mês da consciência negra, e também durante eventos envolvendo a cultura afro-brasileira. Além disso, a casa está tendo um aumento de visitas de afro-brasileiros e turistas da diáspora africana que estão interessados em lugares de lembrança da escravidão em todos os lugares do mundo.]

No mesmo artigo, os autores destacam ainda a proposta narrativa tecida pelo museu:

The narrative presented in this institution and exhibition focuses on two issues: the neighborhood and its historical link with the creation of the city and the history of slavery, and the history of "pretos novos" and the process of archaeological excavations. The institution asserts the history of slavery itself by emphasizing the importance of making this history public, in order to avoid negationism through silence. To achieve this goal, the institute proposes a series of strong statements aimed at raising awareness of the wrongs of slavery. It also provides general information on the more global history of slavery in the context of the Atlantic slave trade. (SAILLANT; SIMONARD, 20I2, p. 224).

[A narrativa apresentada nessa instituição e a exposição concentram-se em dois temas: o bairro e a ligação histórica com a criação da cidade e a história da escravidão; e a história dos pretos novos e o processo de escavação arqueológica. A instituição afirma a própria história da escravidão enfatizando a importância de tornar essa história pública, com o objetivo de evitar o negacionismo através do silêncio. Para alcançar esse objetivo, o instituto propõe uma série de afirmações fortes destinadas a aumentar a conscientização sobre os erros relacionados à escravidão. Ele também fornece informações gerais sobre a história mais global da escravidão no contexto do comércio atlântico de escravos.]

Por meio de uma rede de apoio, o Instituto de Pesquisa e Memória Pretos Novos (RJ) tem conseguido desenvolver suas atividades e, de certo modo, preservar seu acervo. No entanto, entre os problemas enfrentados por alguns dos museus listados no Quadro I, figura a ausência de uma infraestrutura adequada e, consequentemente, a má conservação dos acervos que estão à disposição dessas instituições. Conforme demonstram as fotografias de visitantes disponíveis nas páginas dos museus no site de viagens Tripadvisor (figuras 2, 3, 4 e 5), o Museu do Escravo (RJ) e o Museu Senzala Negro Liberto (CE) têm parte de seus acervos alocados em prédios onde funcionavam antigas senzalas. 
๑ Tripadvisor a

$\vartheta$ Avaliaçäo $\bigcirc$ Viagens $ه$ Alertas

Barra do Piraí Hotéis Oquefazer Restaurantes Voos Pacotes de viagem Cruzeiros Locação de veículos ...

\section{Museu do Escravo - Barra do Piraí}

(๑) (0)

- 14 • \#4 de 6 coisas para fazer em Barra do Pirai • Museus especializados

Visitar o site $\pi$ Enviar e-mail

\section{O que as pessoas estāo dizendo}

"Visita ao Museu do Escravo"

- $\bullet$ dez de 2018

Ao visitar o Museu do Escravo você faz tour, viaja faz historio aprende muito mesmo local lindo arejado, incrivel, emuita natureza ameifazer...

"Viagem no tempo"

-

tudo maravilhosa: alimentação impecável, conservaço do local, atendimento dos funcionários, história do Brasil apresentado.

Recomende alterações para melhorar nosso conteúdo.

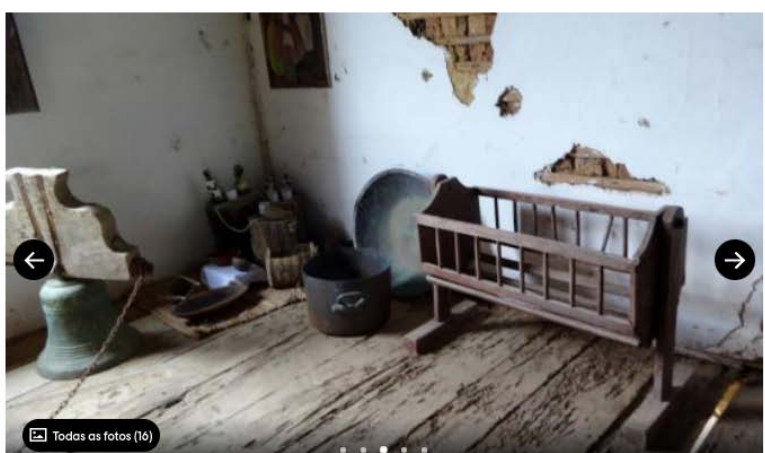

Figura 2 - Itens diversos. Museu do Escravo. Fonte: Tripadvisor, 2016

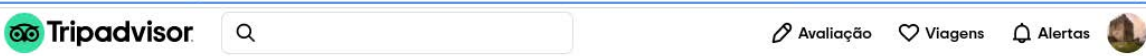

Barra do Pirai Hotéis Oquefazer Restaurantes Voos Pacotes de viagem Cruzeiros Locação de veículos ...

\section{Museu do Escravo - Barra do Piraí}

$00034 \cdot \# 4$ de 6 coisas para fazer em Barra do Pirai • Museus especializados

Visitar o site $\pi$ Enviar e-mail

\section{O que as pessoas estāo dizendo}

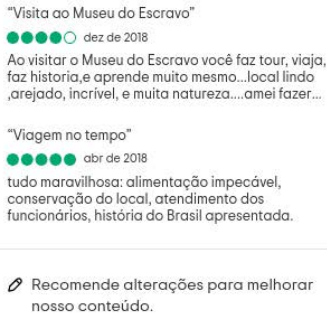

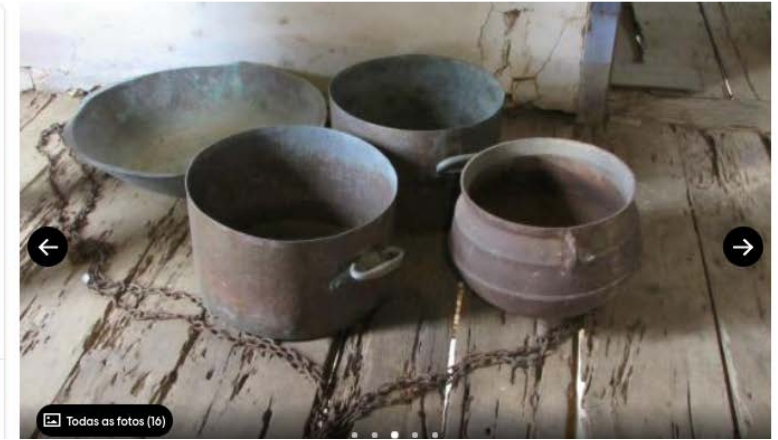

Figura 3 - Recipientes utilizados para cozinhar. Museu do Escravo. Fonte: Tripadvisor, 2015 
ఠ Tripadvisor Q

Redenção Hotẻis Oquefazer Restaurantes Voos Pacotes de viagem Cruzeiros Locação de veículos ...

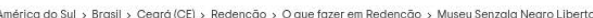

\section{Museu Senzala Negro Liberto - Redenção}

(4) (0)

OOO 44 • \#1 de 4 coisas para fazer em Redenção • Museus especializados

Visitar o site $\pi$ Ligar Enviar e-mail

\section{O que as pessoas estāo} dizendo

(3) Por Livia A

"Uma experiência necessária.

-

Infelizmente é uma mancha na nossa história, mas precisamos conhecer e valorizar o legado dos negros no Brasil. Conhecer este museu é uma

"Visita curta mas que vale a pena"

- $\bullet$ jan de 2018

OMuseu fica aberto todos os dias da semana. Possui algumas máquinas antigas de cana $\theta$

outros mobiliários ao longo do tempo. Ainda hoje

Jvisor.combri/RentalCâr-g2344076-Redencao_State_of_Ceara.heml Ihorar

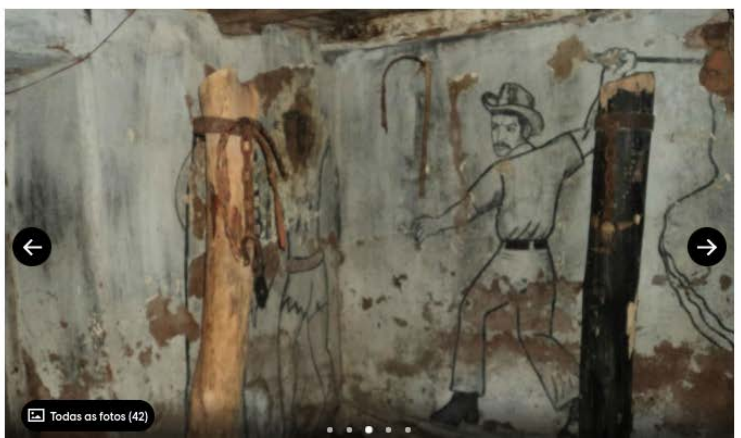

Figura 4 - Escravizado e feitor representados em um desenho pintado na parede do Museu Senzala Negro Liberto. Fonte: Tripadvisor, 2014

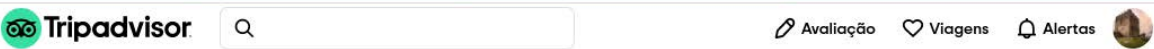
Redenção Hotéis O que fazer Restaurantes Voos Pacotes de viagem Cruzeiros Locação de veículos ...

\section{Museu Senzala Negro Liberto - Redenção}

00044 • \#1 de 4 coisas para fazer em Redenção • Museus especializados

Visitar o site $\pi$ Ligar Enviar e-mail

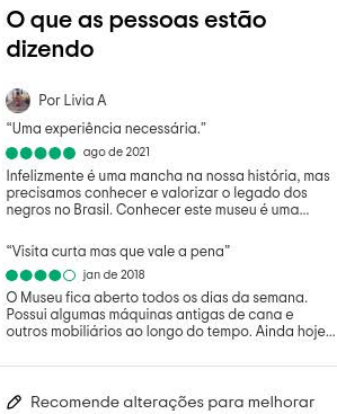

Recomende alterações para melhorar

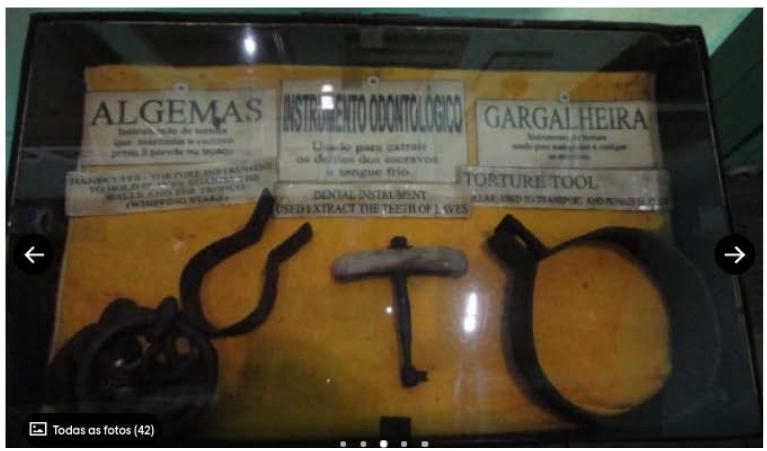

Figura 5-Algemas, instrumento odontológico e gargalheira.

Museu Senzala Negro Liberto. Fonte: Tripadvisor, 2018 
As imagens revelam que ambos os espaços estão em situação de má conservação. São visíveis os buracos nas paredes e nos pisos. Instrumentos de tortura e objetos que pertenceram aos sujeitos escravizados compõem os acervos das duas instituições. Os itens expostos nesses locais ficam, não raro, desprotegidos, sem tratamento adequado e mal preservados.

A análise das imagens acima evidencia também a presença de uma narrativa sobre a escravidão que lança luz sobre as violências praticadas contra sujeitos escravizados. A Figura 4 apresenta um desenho feito em uma das paredes do edifício que abriga o Museu Senzala Negro Liberto (CE). A gravura, provavelmente um registro contemporâneo, buscou retratar uma situação de açoitamento de um escravizado. Cabe registrar que, diferentemente dos objetos que compõem o acervo da instituição, o desenho parece ter sido produzido pela própria equipe do museu, o que expressa, de certo modo, uma contribuição direta da instituição para a produção de narrativas sobre a escravidão.

A vinculação quase imediata entre a violação de corpos negros e a representação da escravidão nos museus é uma questão que tem sido identificada em diferentes países. Sarah Thomas (2013), por exemplo, ao analisar alguns museus britânicos dedicados ao tema, destaca a presença de uma perspectiva narrativa que tende a ressaltar, de modo preferencial, as violências impostas aos corpos dos sujeitos escravizados. A representação da violência que marca esse período da história sem os devidos cuidados éticos pode ter consequências dramáticas. Novamente nos referimos ao trabalho de Myrian Sepúlveda dos Santos, que afirma:

[...] the repetitive imagery of black slaves being beaten, humiliated and injured and the instruments of torture, such as mask and chains reproduce the very same feelings of pain and shame in individuals of the present generation as in their forebears. These images haunt the horizons of those who dream of being free. Researchers who investigate the victims of traumatic experiences assert that compulsive and self-destructive behavior is maintained across subsequent generations, not because of an acknowledgment of what took place, but precisely because of the absence of any full comprehension of what they suffered. The victimization passes through the generations, as the latest identifies with the previous one. (SANTOS, 2008, p. I66).

[...] as imagens repetitivas de escravos negros sendo espancados, humilhados e feridos, e os instrumentos de tortura, como máscaras e correntes, reproduzem nos indivíduos da geração atual os mesmos sentimentos de dor e vergonha sofridos por seus antepassados. Essas imagens assombram o horizonte de quem sonha ser livre. Pesquisadores que investigam vítimas de experiências traumáticas afirmam que o comportamento compulsivo e autodestrutivo se mantém nas gerações subsequentes, não devido a um reconhecimento do que houve, mas justamente devido à ausência de uma compreensão total do que se sofreu. A vitimização atravessa as gerações, já que a mais recente se identifica com a anterior.]

A autora realça a dimensão do trauma que está articulada à história da escravidão e destaca os possíveis efeitos que cenas de violência contra corpos escravizados podem 
causar em públicos que visitam exposições sobre o tema, especialmente públicos negros. A representação banal da violência perpetrada contra sujeitos escravizados parece compor o que Grada Kilomba (20I9) chama de reencenação de um passado traumático por meio do racismo cotidiano. Sendo, portanto, essa abordagem da escravidão uma expressão do racismo, por que tantos museus insistem em tecer esse tipo de vínculo? O trabalho da intelectual portuguesa aponta alguns caminhos que podem contribuir para o entendimento desse cenário:

O trauma [...] raramente é discutido dentro do contexto do racismo. Essa ausência indica como os discursos ocidentais, e as disciplinas da psicologia, e da psicanálise em particular, negligenciaram amplamente a história da opressão racial e as consequências psicológicas sofridas pelas/os oprimidas/os. As/os psicanalistas tradicionais não reconheceram a influência das forças sociais e históricas na formação do trauma (Bouson, 2000; Fanon, I967). Contudo, os dolorosos efeitos do trauma mostram que as/ os africanas/os do continente e da diáspora foram forçadas/os a lidar não apenas com traumas individuais e familiares dentro da cultura branca dominante, mas também com o trauma histórico coletivo da escravização e do colonialismo reencenado e restabelecido no racismo cotidiano, através do qual nos tornamos, novamente, a/o “Outra/o” subordinado e exótico da branquitude. (KILOMBA, 20I9, p. 2I5).

A desvinculação entre trauma e racismo apontada por Grada Kilomba (20I9) é uma pista para pensarmos a insistência por parte das instituições museais em valorizar a dimensão da violência cometida contra escravizados em suas exposições. Seguindo o caminho assinalado pela pesquisadora portuguesa, levantamos o seguinte questionamento: se a psicanálise enfrenta dificuldade para reconhecer a influência das forças sociais e históricas na formação do trauma, as ciências que estudam e buscam retratar os fatos sociais não poderiam, portanto, incorrer em um erro semelhante, negligenciando em suas perspectivas a dimensão do trauma?

Nessa direção, concordamos com Kilomba (20I9) quando classifica a escravidão como um trauma histórico coletivo. Ainda a partir das provocações da autora, pontuamos que o não reconhecimento do racismo como um elemento estruturante das sociedades contemporâneas por parte das instituições museais colabora para que as representações sobre a escravidão tecidas nesses espaços toquem em feridas não cicatrizadas e, possivelmente, criem novos ferimentos. Ademais, abordagens museais sobre a escravidão que não levem em consideração o racismo tendem a ser pouco eficazes na tarefa de criar uma rede de empatia entre o público-alvo e os sujeitos escravizados presentes em suas narrativas.

Entretanto, reconhecer o tema como trauma não significa deixar de abordá-lo. Avaliamos que cenas como as que ocorreram na cidade de Mariana (MG), por exemplo, tornam urgente o debate sobre como as pessoas se relacionam com o tema da escravidão. Dessa forma, concordamos com o argumento de Sarah Thomas (20I3, p. I26) de que os museus precisam enfrentar o desafio de apresentar o que foi a severa realidade das pessoas escravizadas, sem explorar essa situação: "It is important that slavery is understood in its broadest sense; in its quotidian ordinariness but also in its extraordinary brutality" (“É importante que a escravidão seja entendida em seu 
sentido mais amplo; em seu cotidiano ordinário, mas também em sua extraordinária brutalidade”). A autora pondera que, na Inglaterra, alguns passos têm sido dados em direção a uma abordagem mais ampla da escravidão pelas instituições museais, o que tem contribuído, inclusive, para um (re)olhar sobre as imagens de violência retratadas por viajantes dos séculos XVIII e XIX:

[...] when viewed in conjunction with other images of not only quotidian ordinariness but also rebellion and resistance, the narrative becomes one of remarkable resilience. The usual images of brutality in this context serve to emphasise the wonder that forms of resistance took place at all. Some museums today are recognising and incorporating narratives of resistance, and in this area the visual archive is incredibly rich. (THOMAS, 20I3, p. I29).

[(...) quando vista em conjunto com outras imagens não apenas do cotidiano ordinário, mas também de rebeliões e resistência, a narrativa torna-se notavelmente resiliente. A imagem comum da brutalidade nesse contexto serve para enfatizar as maravilhosas formas de resistência que ocorreram. Hoje alguns museus estão reconhecendo e incorporando narrativas de resistência, e essa área do arquivo visual é incrivelmente rica.]

Tecer narrativas que dão conta das inúmeras resistências à escravidão empreendidas pelos sujeitos que foram escravizados tem sido um caminho adotado pelos museus estudados por Thomas (20I3). No entanto, em algumas das instituições indicadas no Quadro I, essa perspectiva ainda enfrenta dificuldades. De acordo com a historiadora Ana Lúcia Araújo, há um processo de invisibilização do agenciamento desses sujeitos nas abordagens museais sobre o tema:

Slavery is presented as part of the history of labour, very often through images from the nineteenth-century European travel accounts and miniature figurines depicting scenes of work and physical punishment. This widespread superficial approach focusing on victimisation and victimhood, constantly associating the Afro-Brazilian population with a passive image, prevents the understanding of slavery as a historical and contemporary phenomenon, concealing its legacies of racism and social inequalities. (ARAÚJO, 2OI2, p. IIO).

[A escravidão é apresentada como parte da história do trabalho, muitas vezes através de imagens dos registros de viajantes europeus do século XIX e miniaturas que retratam cenas do trabalho e punição física. Essa ampla abordagem superficial com foco na vitimização e na falta de agenciamento, constantemente associando a população afro-brasileira a uma imagem passiva, impede a compreensão da escravidão como um fenômeno histórico e contemporâneo, ocultando seus legados de racismo e desigualdades sociais.]

O ponto destacado pela historiadora vai ao encontro da análise das imagens divulgadas no perfil institucional do Museu do Escravo (Belo Vale, MG) na rede social Instagram. Foram selecionadas duas fotos postadas no dia I3 de maio de 2020 , em 
decorrência da comemoração dos I32 anos da Abolição no Brasil (figuras 6 e 7). As imagens acompanhavam o seguinte texto:

Celebramos hoje, I3 de maio, os I32 anos da abolição da escravidão em solo brasileiro. São I32 anos que a Princesa Isabel assinou a Lei de $\mathrm{N}^{\mathbf{0}} 3.353$ que declarava extinta a escravidão no Brasil. O Museu do Escravo também celebra, hoje, 32 anos de existência. São 32 anos resguardando uma parte de nossa história, que foi o período escravocrata vivido no Brasil ao longo de 358 anos. O Museu foi idealizado e construído pelo ilustríssimo Padre José Luciano Jacques Penido e no dia I3 de maio de I988, ano do centenário da abolição, o Museu foi inaugurado em suas atuais dependências. São 32 anos recebendo belo-valenses, turistas e estudantes, convidando-os a formar uma visão crítica do processo de formação do nosso país, bem como a contribuição da mão escrava africana, no progresso do nosso país. Parabéns ao Museu do Escravo pelos 32 anos de história. (MUSEU do Escravo, 2020).

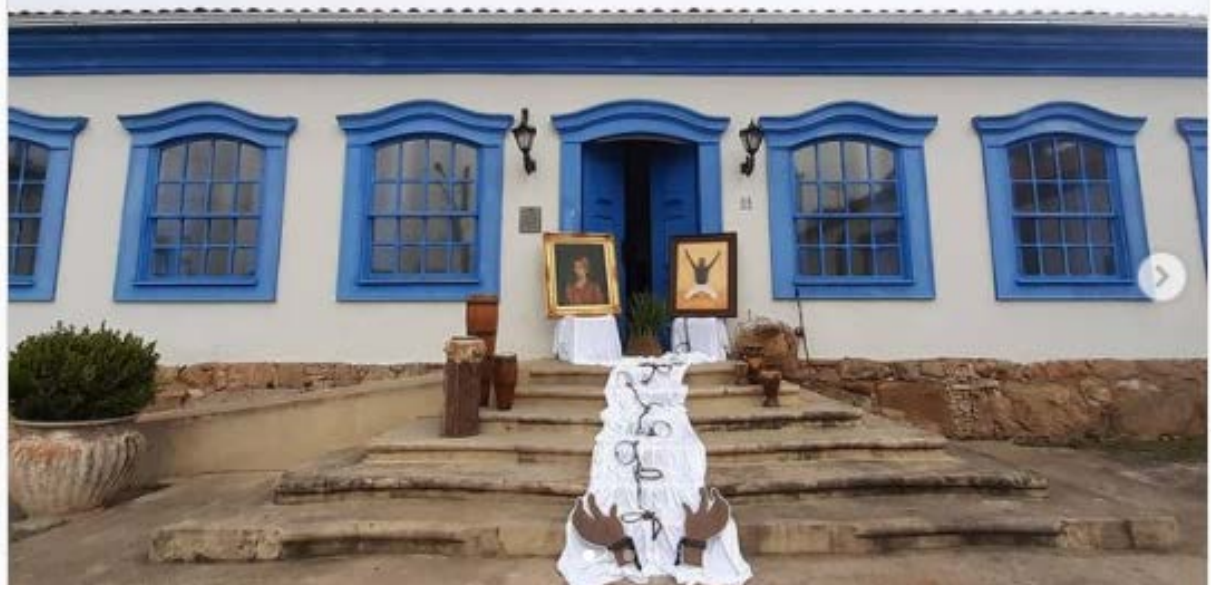

Figura 6 - Entrada do Museu do Escravo (Belo Vale, MG). Museu do Escravo, 2020 


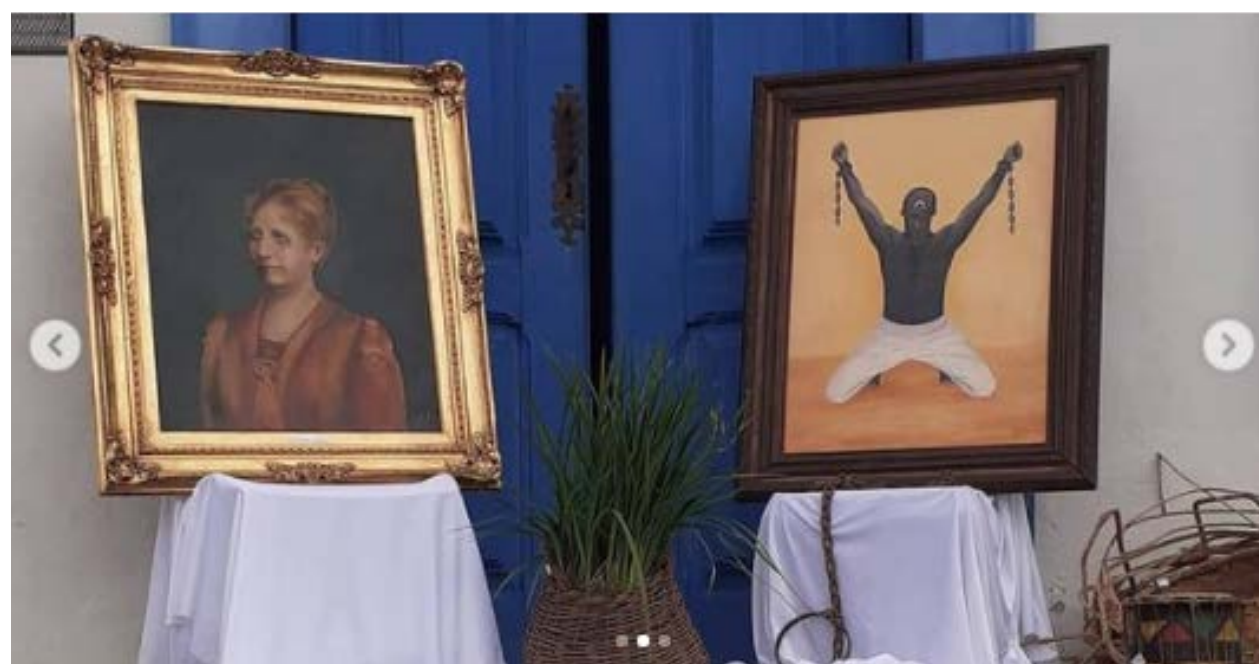

Figura 7 - Princesa Isabel e homem escravizado. Museu do Escravo, 2020

A Figura 6 apresenta uma intervenção artística realizada na entrada do Museu do Escravo (MG) em virtude da celebração do aniversário da Abolição da Escravatura no Brasil. Já a Figura 7 apresenta em detalhe os dois quadros usados na intervenção. À esquerda, pode-se ver a imagem da princesa Isabel; à direita, a de um sujeito escravizado. A análise dos dois quadros evidencia a construção de uma perspectiva por parte do Museu do Escravo (MG) sobre a Abolição da Escravatura no Brasil que visibiliza a imagem redentora da monarquia brasileira, representada pela princesa Isabel. A imagem do sujeito escravizado com correntes quebradas e braços levantados ao céu como se agradecesse por uma dádiva pode expressar, ainda, a ideia de que os indivíduos submetidos à condição de escravos não tiveram autoria no processo de abolição no Brasil. No comunicado divulgado com as imagens destacadas, não há referência alguma à importância dos grupos abolicionistas para o fim da escravidão, diferentemente do que a produção historiográfica contemporânea demonstra:

A historiografia tem nos apresentado a grupos associativos que assumiram a abolição como algo intrínseco à luta dos trabalhadores oitocentistas. É o que nos informa Beatriz Loner, ao mapear entidades de beneficência negras ou operárias, como a Feliz Esperança, Fraternidade Artística e Harmonia dos Artistas, que angariavam doações para alforriar escravos no Rio Grande do Sul, onde havia cerca de 35 entidades com o mesmo propósito e perfil. Longe de serem uma especificidade local, tais associações foram formadas em diversas províncias. (ALBUQUERQUE, 20I8, p. 330).

O I3 de maio é um dia especialmente importante para as instituições listadas no Quadro I. Além de ser a data em que ocorreu a assinatura da Lei Áurea, o dia marca o aniversário de fundação de alguns dos seis museus sobre escravidão no Brasil. É o caso, por exemplo, do Museu da Abolição (PE), que celebrou, em 2020, 37 anos de existência. A instituição publicou em seu perfil oficial na rede social Instagram um manifesto sobre os I32 anos da Abolição: 
I3 de maio não representa o nosso propósito junto à comunidade Afro-brasileira.

Não por acaso, o Museu da Abolição teve sua inauguração, nesta mesma data, no ano de I983, com a exposição temporária "O processo abolicionista através dos textos oficiais". Muita coisa mudou durante esses 37 anos, inclusive a forma como fomentamos nosso trabalho, nossas pesquisas e nossas ações.

Escolhemos um lado: às narrativas emancipatórias, aquelas que não acreditam que a abolição foi o fim das mazelas coloniais e dos crimes contra a população afro.

Nossa atual população negra convive com o resultado de roubos, mortes, destruições e alienações, que derivam ainda da colonização e do processo escravista.

[...]

Devemos muito à população negra deste país, principalmente uma dinâmica emancipatória, que só pode ser construída com uma sociedade antirracista e que esteja pronta para dialogar e repensar seus privilégios.

Convidamos às instituições, e toda sociedade civil, adotarem uma postura antirracista REAL. (MUSEU da Abolição, 2020).

Diferentemente do Museu do Escravo (MG), o Museu da Abolição (PE) apresenta uma perspectiva de contestação sobre os significados da celebração da abolição no Brasil. Um dos trechos do manifesto cita, inclusive, os dados da desigualdade racial no Brasil contemporâneo, relacionando-os à falta de apoio político e econômico aos milhares de sujeitos libertos após a assinatura da Lei Âurea pela princesa Isabel, em I3 de maio de I888. O modo como as duas instituições expressam posicionamentos distintos sobre um mesmo fato histórico visibiliza, em certa medida, o caráter ideológico dos espaços museais, marcados por conflitos políticos e disputas sobre como as narrativas são construídas.

Chama ainda a atenção o uso da palavra "crime" por parte do Museu da Abolição (PE). Em um crime, existe a figura da vítima. Contudo, quando usada para pensar a instituição da escravidão, o campo semântico dessa palavra tem colaborado para reforçar o seguinte cenário descrito por Paul Gilroy (20I2, p. 355): "A escravidão torna-se um feixe de associações negativas, que é melhor deixar para trás”. Nessa mesma direção, há uma vinculação, quase que imediata, entre a ideia de vítima e a falta de agenciamento por parte dos sujeitos escravizados.

Todavia, a articulação proposta no manifesto do Museu da Abolição (PE) nos sugeriu um importante diálogo com o trabalho de Mônica Lima (20I8), que, ao responder à pergunta "por que escolher narrativas sublinhando a dor da escravidão sobre a história do Cais do Valongo?”, explica:

[...] porque a escolha por um caminho pela região do Cais do Valongo faz lembrar que o tráfico atlântico de africanos escravizados foi um crime contra a humanidade e - vale recordar - o Brasil ainda não o reconheceu oficialmente como tal. Num crime, há vítimas. Nem de longe essa ideia implica na concepção dos escravizados como sujeitos -objetos, transformados em mercadorias e submetidos sem reação. Não se trata dessa qualidade de vítima. Trata-se da história dos que sofreram e nos legaram essa memória. O ser vítima não significa perder a capacidade de agir e mesmo de transformar. (LIMA, 20I8, p. IO6). 
As questões levantadas nos trabalhos de Paul Gilroy (20I2) e Mônica Lima (20I8) permeiam as discussões sobre o processo de musealização da escravidão. Reconhecer a escravidão como crime contra a humanidade requer pensar a existência de vítimas, como ponderou a historiadora. Contudo, cabe a reflexão sobre qual é a categoria de vítima apresentada nas exposições dos museus brasileiros. Trata-se de uma representação de vítima que constrange e humilha a população negra ou que possibilita e convida a sociedade brasileira a pensar sobre os horrores desse crime? Como essas instituições têm lidado com o desafio de representar esse expressivo período da história do Brasil, tendo em vista que o tema constitui, nas palavras de Grada Kilomba (20I9), um trauma histórico coletivo? Essas foram algumas questões que mobilizaram a escrita deste ensaio.

\section{CONSIDERAÇõES FINAIS}

Como buscamos demonstrar, o tráfico transatlântico de pessoas escravizadas e a escravidão de africanos no Brasil estão inseridos em uma rede de múltiplos significados. Para determinados grupos, os eventos são vistos apenas como fatos históricos (ainda que se tente invisibilizá-los) pertencentes à trajetória da nação brasileira, podendo, por vezes, ser revisitados por meio de encenações jocosas. Para outros setores, os eventos representam crimes contra a humanidade e não podem ser compreendidos à parte da dimensão do trauma criado pelos horrores que marcaram o período.

Nesse cenário, estão inseridas as pouquíssimas instituições museais dedicadas exclusivamente à temática, que podem ser entendidas como reflexos, mas também refletoras desse complexo campo. Conforme demonstra a análise de imagens de itens de acervo disponíveis na internet e das postagens nas redes sociais dos museus identificados, uma parcela significativa das instituições tem colocado em evidência narrativas que, em certa medida, banalizam as violências cometidas contra os sujeitos escravizados. A representação dos horrores da escravidão, sem levar em consideração as dimensões éticas, corre o risco de ser apenas o que Grada Kilomba (20I9) denomina de reencenação de um passado traumático.

Entretanto, a análise também revelou algumas potencialidades interessantes nas abordagens museológicas da escravidão, como o apontamento realizado pelo Instituto de Pesquisa e Memória Pretos Novos (RJ) sobre a dimensão global do tráfico transatlântico de pessoas escravizadas (SAILLANT; SIMONARD, 20I2). O instituto tem exercido um forte posicionamento em relação à divulgação de uma memória que, como expressa o baixo investimento do poder público, está inserida em um projeto de esquecimento.

Ademais, consideramos fundamental pontuar a necessidade de a musealização do tráfico transatlântico de pessoas escravizadas e da escravidão estar articulada a um debate sobre a promoção de práticas educativas antirracistas. Do contrário, corre-se o risco de perpetuar representações desses eventos que causam sofrimento, constrangimento, mas não geram empatia e 
não contribuem para a promoção da dignidade humana, princípio que orienta o Estatuto de Museus (BRASIL, 2009).

Assinalamos ainda a importância do diálogo com a produção historiográfica sobre a temática, com destaque para as perspectivas que consideram o protagonismo e a agência dos sujeitos escravizados, e do entendimento da escravidão como um tema sensível, não como um conjunto de experiências marginais ou uma nota de rodapé expandida, como adverte Toni Morrison:

Por mais que a análise histórica tenha mudado (e mudou enormemente) e se tornado mais abrangente nos últimos quarenta anos, os silêncios sobre certas populações (minorias), quando finalmente articulados, ainda são entendidos como relatos suplementares de uma experiência marginal; um registro suplementar, dissociado da história oficial; uma nota de rodapé expandida, por assim dizer, que é interessante, mas de pouca centralidade no passado da nação. (MORRISON, 2020, p. 363).

No processo de musealização da escravidão, é preciso combater perspectivas e leituras cristalizadas, as quais reforçam preconceitos, estereótipos e o entendimento da pessoa escravizada como coisa, como mercadoria. Segundo Nilma Lino Gomes (20I2, p. 99), "vivemos um momento ímpar no campo do conhecimento. O debate sobre a diversidade epistemológica do mundo encontra maior espaço nas ciências humanas e sociais. É nesse contexto que a educação participa como um campo que articula de maneira tensa a teoria e a prática”.

Propomos, assim, uma "descolonização" dos museus e suas práticas, pois é preciso considerar outras epistemologias e reivindicar políticas públicas no combate ao racismo estrutural. Num país de população majoritariamente negra, o direito à memória e ao passado da maior parte de seus cidadãos não pode continuar sendo negado. É preciso reconhecer outros paradigmas epistemológicos, questionar seleções, escolhas, e confrontar a colonialidade do saber e as perspectivas exclusivamente eurocêntricas (QUIJANO, 2005). Reconhecer a escravidão como um crime contra a humanidade e um trauma histórico coletivo é também parte do movimento necessário de reparação histórica no tempo presente. Talvez, dessa forma, cenas que articulam braços nas argolas e sorrisos nos rostos não sejam mais encaradas como uma simples brincadeira, uma maneira jocosa de encenar o passado. 
VINíCIUS OLIVEIRA PEREIRA é doutorando no Programa de Pós-Graduação em Educação da Universidade do Estado do Rio de Janeiro (ProPed/ UERJ) e pesquisador do Núcleo de Estudos AfroBrasileiros da UERJ.

viniciusoliveirapereira@yahoo.com.br

https://orcid.org/oooo-0003-0838-3248

ALEXANDRA LIMA DA SILVA é professora da Faculdade de Educação da Universidade do Estado do Rio de Janeiro (UERJ). alexandralimaro75@gmail.com

https://orcid.org/0000-0002-0310-7896

\section{REFERÊNCIAS}

ALBUQUERQUE, W. Movimentos sociais abolicionistas. In: SCHWARCZ, L. M.; GOMES, F. (org.), Dicionário da escravidão e liberdade: 50 textos críticos. I. ed. São Paulo: Companhia das Letras, 20I8, p. 328-333. ALENCASTRO, L. F. África, números do tráfico atlântico. In: SCHWARCZ, L. M.; GOMES, F. (org.). Dicionário da escravidão e liberdade: 50 textos críticos. I. ed. São Paulo: Companhia das Letras, 2018, p. 57-63.

ARAÚJO, A. L. Zumbi and the voices of the emergent public memory of slavery and resistance in Brazil. Comparativ: Zeitschrift für Globalgeschichte und vergleichende Gesellschaftsforschung, 2012, 95-III.

ARAÚJO, A. L. Slavery in the age of memory: engaging the past. London: Bloomsbury, 202Ia

ARAÚJO, A. L. Museums and Atlantic slavery. London: Routledge, 202Ib.

BRASIL. Presidência da República. Casa Civil. Subchefia para Assuntos Jurídicos. Lei n. II.904, de I4 de janeiro de 2009. Institui o Estatuto de Museus e dá outras providências. Disponível em: http://www. planalto.gov.br/ccivil_03/_ato2007-2010/2009/lei/lII904.htm. Acesso em: I4 mar. 202I.

CONFERÊNCIA de Durban. Declaração e programa de ação. III Conferência Mundial contra o Racismo, Discriminação Racial, Xenofobia e Intolerância Correlata. Durban, 200I. Ministério da Cultura/ Fundação Cultural Palmares. Disponível em: http://www.unfpa.org.br/Arquivos/declaracao_durban. pdf. Acesso em: 5 mar. 202I.

FERNANDES, E. O pelourinho denuncia Mariana. 28 set. 20I7. Jornal Ponto Final. Disponível em: http:// www.jornalpontofinalonline.com.br/noticia/5775/o-pelourinho-denuncia-mariana. Acesso em: 20 abr. 2020.

GILROY, P. O Atlântico negro: modernidade e dupla consciência. Trad. Cid Knipel Moreira. 2. ed. São Paulo: Editora 34, 2012.

GOMES, N. L. Relações raciais e descolonização dos currículos. Currículo sem Fronteiras, v. I2, n. I, 20I2, p. 98-I09.

IBRAM - Instituto Brasileiro de Museus. Museus do Brasil. Disponível em: https://www.museus.gov.br/ museus-do-brasil/. Acesso em: I9 abr. 2020. 
IPN - Instituto de Pesquisa e Memória Pretos Novos. Disponível em: http://pretosnovos.com.br/museumemorial. Acesso em: I6 maio 2020.

KILOMBA, G. (20I9). Memórias da plantação: episódios de racismo no cotidiano. Trad. Jess Oliveira. I. ed. Rio de Janeiro: Cobogó, 2019.

KLEIN, H. S. Demografia da escravidão. In: SCHWARCZ, L. M.; F. GOMES, F. (org.). Dicionário da escravidão e liberdade: 50 textos críticos (I. ed., pp. I85-I94). São Paulo: Companhia das Letras, 2018.

LIMA, M. História, patrimônio e memória sensível: o Cais do Valongo no Rio de Janeiro. Outros Tempos, V. I5, n. I6, 20I8, 98-III. Disponível em: https://www.outrostempos.uema.br/index.php/outros_tempos_uema/article/view/657/pdf. Acesso em: 5 maio 2020.

MORRISON, T. A fonte da autoestima. São Paulo: Companhia das Letras, 2020.

MUSEU da Abolição [@museuabolição]. I3 de maio não representa o nosso propósito junto à comunidade afro-brasileira [fotografia]. I3 maio 2020. Instagram. Disponível em: https://www.instagram.com/p/ CAIgi5cDHtX/?igshid=a4dmpgbr2md8. Acesso em: 5 jun. 2020.

MUSEU do Escravo [@museudoescravo]. (2020, I3 maio). Celebramos hoje, I3 de maio, os I32 anos da abolição da escravidão em solo brasileiro [fotografia]. I3 de maio 2020. Belo Vale. Instagram. Disponível em: https://www.instagram.com/p/CAIJ93bgLBz/?igshid=b9ybit5dfzow. Acesso em: Io jun. 2020.

MUSEU do Escravo. Utensílios dos escravos. Barra do Piraí, RJ [foto de viajante]. Jul. 20I5. Tripadvisor. Disponível em: https://bit.ly/2W6HxZx. Acesso em: I8 maio 2020.

MUSEU do Escravo. Fazenda Ponte Alta. Barra do Piraí, RJ [foto de viajante]. Maio 20I6. Tripadvisor. Disponível em: https://bit.ly/2WagoGh. Acesso em: I8 maio 2020.

MUSEU Senzala Negro Liberto. Espaço de tortura [foto de viajante]. Maio 2014. Tripadvisor. Disponível em: https://bit.ly/3zoNANO. Acesso em: I8 maio 2020.

MUSEU Senzala Negro Liberto. Instrumentos de tortura [foto de viajante]. Jan. 20I8. Tripadvisor. Disponível em: https://bit.ly/3xYk9KN . Acesso em: I8 maio 2020.

NORA, P. Entre memória e história: a problemática dos lugares. Tradução: Yara Aun Khoury. Projeto História. Revista do Programa de Estudos Pós-Graduados em História e do Departamento de História da PUC-SP, v. Io, I993, p. 7-28. Disponível em: https://revistas.pucsp.br/index.php/revph/article/ view/I2IOI. Acesso em: 7 jul. 2020.

PEREIRA, J. C. M. À flor da terra: o Cemitério dos Pretos Novos no Rio de Janeiro. Dissertação (Mestrado em História Social). Instituto de Filosofia e Ciências Sociais, Universidade Federal do Rio de Janeiro, 2006. Disponível em: http://objdig.ufrj.br/34/teses/JulioCesarMedeirosDaSilvaPereira.pdf. Acesso em: I ${ }^{\circ}$ ago. 2020.

QUIJANO, A. Colonialidade do poder, eurocentrismo e América Latina. In: LANDER, Edgardo (org.). A colonialidade do saber: eurocentrismo e ciências sociais - perspectivas latino-americanas. Buenos Aires: Clacso, 20I5, p. 227-278.

SAILLANT, F.; SIMONARD, P. (20I2). Afro-Brazilian heritage and slavery in Rio de Janeiro community museums. In: ARAÚJO, Ana Lúcia (org.). Politics of memory: making slavery visible in the public space. London: Routledge, 20I2, p. 2I3-23I.

SANTOS, M. S. The repressed memory of Brazilian slavery. International Journal of Cultural Studies, v. II, n. 2, 2008, p. I57-I75. https://doi.org/Io.II77/I367877908089262

THOMAS, S. Violence and memory: slavery in the museum. In: RYCROFT, D. (ed.), World art and the legacies of colonial violence. Farnham: Ashgate Publishing, 2013, p. п13-г32.

VIRGÍlIO, P. Marco da escravidão, Instituto dos Pretos Novos luta por recursos para se manter. 15 abr. 2017. Agência Brasil. Disponível em: https://bit.ly/3zoZDdV. Acesso em: I8 maio 2020. 